\title{
Is Sexual Attraction Independent of the Instrumental and Expressive Traits?
}

\author{
Juan Fernández, María Ángeles Quiroga, and Isabel Del Olmo \\ Universidad Complutense de Madrid
}

\begin{abstract}
Sexual attraction is an essential part of sex, just as the instrumental and expressive traits are the mainstay of gender. Various hypotheses concerning the dimensionality and independence versus dependence/overlapping of these core entities were tested. A group of 423 university students completed the Sexual Attraction Questionnaire (SAQ; Fernández, Quiroga, \& Rodríguez, 2006) and the 12-item Bem Sex Role Inventory (BSRI; Bem, 1974). Internal consistency and factor analyses (PAF) were conducted. The results support the dimensionality established for the SAQ and reveal some psychometric and conceptual weaknesses of the 12-item BSRI. The results also support the independence of the two cores: sexual attraction and the instrumental and expressive traits. The logical implications for the different viewpoints of the relations between sex and gender are discussed. Keywords: sexual orientation, sexual attraction, instrumentality, expressiveness, masculinity, femininity
\end{abstract}

Uno de los núcleos básicos de la realidad del sexo es la atracción sexual, al igual que uno de los núcleos básicos de género hace referencia a los dominios instrumental y expresivo. En este trabajo se van a poner a prueba las distintas hipótesis sobre la dimensionalidad de la atracción sexual y de los dominios instrumental y expresivo, a la par que la hipótesis de la independencia frente a la dependencia o solapamiento de ambas realidades. Se contó para ello con la participación de 423 estudiantes universitarios. Los instrumentos utilizados fueron el Cuestionario de Atracción Sexual (CAS; Fernández, Quiroga, \& Rodríguez, 2006) y la versión de 12 ítems del Bem Sex Role Inventory (BSRI; Bem, 1974). Los resultados proporcionaron un claro apoyo empírico a la dimensionalidad establecida para el SAQ, a la par que dejaron al descubierto ciertas debilidades conceptuales y psicométricas del BSRI. Los resultados apoyan la independencia de los dos núcleos: la atracción sexual y los dominios instrumental y expresivo. Se establecen las implicaciones lógicas para las distintas posturas en torno a las relaciones del sexo y el género.

Palabras clave: atracción sexual, orientación sexual, instrumentalidad, expresividad, masculinidad, feminidad

We would like to thank the university centers where this research was carried out for their collaboration. We would also like to thank Dr. Miguel Ángel Mateo for his thorough comments.

Correspondence concerning this article should be addressed to Juan Fernández, Departamento de Psicología Evolutiva y de la Educación, Facultad de Psicología, Campus de Somosaguas. 28223 - Madrid (Spain). E-mail: jfernandez@psi.ucm.es

The SAQ is available to any interested researcher (jfernandez@psi.ucm.es).

Translation: Virginia Navascués Howard 
Within the complex reality of sex, specifically in the field of sexology, Kinsey, Pomeroy, and Martin (1948) made an effort to operationalize sexual orientation by means of a scale in the mid $20^{\text {th }}$ century. Since then, new instruments have been designed to examine the dimensions of sex (Davis, Yarber, Bauserman, Schreer, \& Davis, 1997). Up till now, sexual orientation, exclusively with regard to its dimensionality, has been conceived in one of the following ways:

1. Two opposite categories-heterosexuality versus homosexuality-with no overlapping, the predominant conception during the first half of the $20^{\text {th }}$ century (Sell, 1997).

2. A bipolar continuum-homosexuality at one end and heterosexuality at the other, with bisexuality in the middle, the Kinseyian conception (Kinsey et al., 1948). The assessment scale ranges from 0 (heterosexuality with no homosexuality) to 6 (homosexuality with no heterosexuality).

3. Two dimensions that split the Kinseyian continuum into homosexuality on the one hand, and heterosexuality on the other (Shively \& De Decco, 1977). Although independent, these two dimensions are measured with the same scale, ranging from 0 to 6 .

4. An orthogonal bidimensionality: These two dimensions of homosexuality and heterosexuality are described as independent or not closely related (Storms, 1980). This approach is based on the orthogonal bidimensionality of the masculinity and femininity scales that appeared in the mid 70s (see below).

5. Multidimensional: The dimensions reflect aspects or components such as sexual attraction, sexual behavior, sexual fantasies, emotional preference, social preferences, self-identification, and hetero/homo lifestyles (Berkey, Perelman-Hall, \& Kurdek, 1990; Coleman, 1987; Kinnish, Strassberg, \& Turner, 2005; Klein, 1990; Klein, Sepekoff, \& Wolf, 1985). The multidimensionality of sexual orientation is currently assumed by most researchers, regardless of the total number of dimensions or their possible meaning (Davis et al., 1997).

Only recently has sexual attraction become more independent of sexual orientation, a considerably broader construct that includes sexual attraction (Fernández, Quiroga, \& Del Olmo, 2006; Narring, Stronski Huwiler, \& Michaud, 2003). The expression sexual attraction as such was included in the Thesaurus of Psychological Index Terms in 2003 (Gallagher, 2005). Hence, only recently have researchers attempted to test its dimensionality (Fernández, Quiroga, \& Rodríguez, 2006). Taking into account the aforementioned most familiar conceptions of sexual orientation-with reference to dimensionality (the essential framework to be able to understand the dimensionality of sexual attraction nowadays) - these authors defined sexual attraction as a subject's inclination or desire to engage in sexual relations with a person of one sex versus the other sex, with people of both sexes, or with neither sex. This definition produces the fourfold typology - people attracted to women, to men, to both sexes, or to neither-used in the Diagnostic and Statistical Manual of Mental Disorders (4 ${ }^{\text {th }}$ ed., text revision; American Psychiatric Association, 2000). With regard to dimensionality, Fernández, Quiroga, and Rodríguez (2006) established that sexual attraction can either be considered a bipolar dimension (one factor with positive loadings on some items and negative loadings on the rest) or two inversely related dimensions (two negatively correlated factors), as they are the same thing conceptually and mathematically. According to these authors, this conception is based on the facts that, at present, in most populations: (a) a large percentage of men display sexual attraction to women, and a large percentage of women show sexual attraction to men; (b) a certain percentage of men and women will feel attracted to persons of the same sex; c) some men and women will feel attracted to persons of both sexes; and (d) a minimum percentage of men and women will not show obvious sexual attraction to either sex. This proposed dimensional structure will only emerge in populations or samples in which there is a manifest predominance of mutual attraction between men and women.

This delimitation of sexual attraction, as opposed to the broader (multidimensional) construct of sexual orientation (which is not the direct target of this work), requires even more qualification and clarifications. Firstly, an individual's sexual attraction at any point in life does not mean that it will remain unchanged throughout the person's lifetime (Greene, \& Croom, 2000; Rossi, 1994). Secondly, certain groups of individuals, such as hermaphrodites, pseudohermaphrodites, ambiguous individuals, or transsexuals, as well as cultures different from the western culture, were not included in this study. Thirdly, this is a descriptive work, not an explanatory or an evaluative one; hence, no assumptions are made about the reasons (biological or social) for a person's feeling attracted to both sexes, to men, to women, or to neither sex (for causal analyses, see: Evans, 1993; Geer \& O'Donohue, 1987; Kitzinger, 2001). Fourthly, an individual's specific sexual attraction at a certain point in life does not imply that the person does not feel other kinds of simultaneous attractions, either concordant or discordant, towards another sex, which could be a part of the complex gender reality-that is, a girl can feel sexually attracted to men and at the same time prefer women as research team comrades, companions with whom to go to the movies, to the theater, or on vacations, among many other attractions (this complexity can be observed in Beall \& Sternberg, 1993; Gergen \& Davis, 1997; Lippa, 2005; Rossi, 1985; Talburt \& Steinberg, 2000; Unger, 2001; Worrel, 2001). Fifthly, the study of sexual attraction is limited to a line of psychology that endeavors to elaborate assessment instruments for previously delimited constructs-in this case, 
for sexual attraction and not sexual orientation, as a handbook of the diverse instruments developed for measuring the latter, which covers up to the end of the $20^{\text {th }}$ century, has already been published (Davis et al., 1997).

With regard to gender, the instrumental and expressive traits are widely used to operationalize one of its central points. The first attempts to operationalize gender were made in the first half of the $20^{\text {th }}$ century when the first masculinity/femininity scales were developed (Gough, 1952; Hathaway \& McKinley, 1943; Terman \& Miles, 1936, among others). With these scales, researchers hoped to differentiate men and women who displayed a functional or "normal" development from those who presented a dysfunctional one. The so-called congruence model was predominant at that time: In order to achieve their "normal" development, men (sex) should be masculine (gender) and women (sex) should be feminine (gender). As more data were collected with masculinity/femininity scales, it became more and more obvious that the model had no empirical support, which led to the so-called crisis of the classical model (for a critical review and synthesis, see Constantinople, 1973).

The essence of masculinity/femininity is no longer defined by apparent sexual dimorphism (sexual reality) but by a theoretical conception: the instrumental and expressive traits (Parsons \& Bales, 1955). Other conceptions, such as those of Bakan (1966) and Koestler (1967, 1978), by and large coincide with this one. Their common denominator is the habitual and differential social roles performed by each sex (Helgeson, 1997; Stake, 1997). In the 60s, these theoretical efforts were operationalized in the so-called new scales of masculinity and femininity, implying the total independence of these two dimensions (Bem, 1974; Spence, Helmreich, \& Stapp, 1975). After hundreds of empirical works using these instruments over the last three decades, the results concerning the number of dimensions evaluated by these scales are inconclusive, especially in the case of the Bem Sex Role Inventory (BSRI; Bem, 1974). From a theoretical viewpoint, perhaps the main issue concerning this instrument is to stop calling them "masculinity and femininity" scales (these scales were not based on any theory about these concepts) and start calling them, once and for all instrumentality and expressiveness scales - assuming, at this point, that the theory established to uphold them is still valid (Spence \& Buckner, 2000; Spence, Helmreich, \& Holahan, 1979; Zhang, Norvilitis, \& Jin, 2001). The conceptual framework that Bem proposed over the last 25 years in some of her works as an update of these constructs (masculinity, femininity, instrumentality, expressiveness) is her gender schema theory (Bem, 1981, 1993). However, the problem is still there, because this theory-which dichotomizes people as genderschematic versus gender-aschematic - is based on individuals' prior classification by the BSRI as masculine, feminine (schematic), androgynous, or undifferentiated (aschematic). Therefore, it seems appropriate to examine: (a) the possible meaning of the items in terms of masculinity/ instrumentality or femininity/expressiveness; and (b) the meaning of the underlying dimensionality of these items, because, as indicated by Signorella (1999), Bem's dualistic model (BSRI and gender schema theory) has very probably led both to the multifactoriality of the BSRI and the multidimensionality of gender schemas instead of the bidimensionality of the gender schema theory.

With regard to dimensionality, either of sexual attraction or of the instrumental and expressive traits, several questions immediately arise. Concerning sexual attraction: Will the empirical data replicate the hypothesis of the bipolar dimension (the inversely related bidimensionality)? Concerning the instrumental and expressive traits: Should we refer to bidimensionality, in keeping with Bem (1974) and Spence et al.'s (1975) original conception, or to multidimensionality, as the empirical data obtained from the BSRI seem to imply (for a recent review, see Choi \& Fuqua, 2003)? Moreover, what relationship should we hypothesize between these dimensions: practically null (according to Bem and Spence), positive, or negative (as reported in some works over the last 30 years)? In addition, what relation can be established between sexual attraction and the instrumental and expressive traits, given that sexual attraction belongs to the sphere of sex, whereas the traits belong to that of gender?

As hypotheses, we postulate the following four predictions. First, the Sexual Attraction Questionnaire (SAQ; Fernández, Quiroga, \& Rodríguez, 2006)) will yield either one bipolar dimension or two negatively-related dimensions, because, according to the authors, they are the same thing.

Second, the "new scales"-specifically the BSRI—called masculinity and femininity scales (although their purpose is to operationalize the instrumental and expressive traits), are more multidimensional than bidimensional, an aspect that was not particularly emphasized during their elaboration (their starting point was always bidimensionality). If this hypothesis receives empirical support, the foundations of the gender schema theory may quake, as they are based on a doubly dualistic model: the model on which the BSRI was based and the gender-schematic versus gender-aschematic people model (Bem, 1985); in contrast, this study may lend empirical support to Signorella's (1999) alternative proposal of multidimensionality.

Third, according to Bem's (1974) accounts, no significant relations, particularly negative relations, will be revealed between the instrumental and expressive factors because this would provide clear empirical support for the congruence model (men should develop masculinity and women femininity), which, in fact, she considered mistaken.

Fourth, the BSRI and SAQ items will define separate factors with little relationship, given the assumed independence of sex (sexual attraction) and gender traits (Fernández, 2000), in contrast to the relations established in other proposals (Desrochers, 1995; Finlay \& Scheltema, 1991; Green \& Kendrick, 1994). 


\section{Method}

\section{Participants}

A total of 423 university students ( 235 women and 188 men) completed the two evaluation instruments used in this study. Mean age was 19.9 years $(\mathrm{SD}=2.0)$, ranging from 17 to 27 years. Of the total, $55.6 \%$ were first-year students, $26.7 \%$ second-year students, $10.6 \%$ were in their fourth year, and the rest (4\% and 3.1\%) were in their third and fifth year, respectively. The majority had chosen the teaching specialty $(58.9 \%), 20.3 \%$ medical sciences, $11.8 \%$ psychology, $5 \%$ political sciences, and $4 \%$ biological sciences.

\section{Instruments}

The Sexual Attraction Questionnaire (SAQ; Fernández, Quiroga, \& Rodríguez, 2006). This instrument, comprised of 17 items -9 of attraction to women and 8 of attraction to men, was used to appraise sexual attraction. The items are meant to express certain aspects of what is considered sexual attraction by researchers, professionals, and students. These items refer to behaviors ("Sometimes I feel like seducing men"), thoughts ("I like to think that men notice me"), emotions ("When I fall in love with a man, I often think of him"), and social image ("In my gang, they know that I am attracted to women"). Participants rate the items on a 7-point Likert-type scale, ranging from 1 (totally disagree) to 7 (totally agree). Both scales (Attraction to Women and Attraction to Men) obtained satisfactory internal consistency, with Cronbach's alpha values of .98. Concerning construct validity, the results of factor analyses supported both the inversely related bidimensionality and the bipolar unidimensionality (Fernández, Quiroga , \& Del Olmo, 2006; Fernández, Quiroga, \& Rodríguez, 2006).

The Bem Sex Role Inventory (BSRI, Bem, 1974). In order to evaluate the instrumental and expressive traits, we chose the BSRI from among other instruments because internationally it is the most extensively used scale (Beere, 1990), despite some conceptual and methodological criticisms (Marsh, Antill, \& Cunningham, 1989; Spence, 1991). However, at present, this scale operationalizes the instrumentality/masculinity and expressiveness/femininity traits better than any other. We used a reduced version made up of the 12 best items from Bem's (1974) original scale. To select these 12 items, we took the following aspects into account: (a) the items included in Antill and Russell's (1980) short version; (b) the items from Bem's (1981) own short version; and (c) the most consistent (higher loadings and higher communality value) and coherent items, both in the exploratory and confirmatory factor analyses performed in various contexts and countries (Mateo \& Fernández, 1991).

\section{Procedure}

The SAQ and the 12-item BSRI were administered conjointly by the third author and the teacher who was lecturing at that time, after requesting permission both from the teacher and the students. Students were especially asked to answer sincerely so that the research would be of some value, and were informed that their responses were anonymous. At no time were they told what was being evaluated with the SAQ.

\section{Data Analysis}

Exploratory principal axis factor analyses (PAF) were conducted to test the dimensionality hypotheses of the instruments employed. Analysis of internal consistency (Cronbach's alpha coefficient) was also performed to determine reliability. The SPSS 12.0 was employed for these analyses.

\section{Results}

Regarding the SAQ, the KMO measure of sampling adequacy was .97 . Bartlett's sphericity test $(12019.5, p<$ .001) clearly showed that the items are substantially related.

The results of PAF of the SAQ are displayed in Table 1. The data clearly support a bipolar dimension of sexual attraction. This bipolar factor accounts for $80.1 \%$ of the variance. Items with positive factor loadings measure Attraction to Women and those with negative loadings measure Attraction to Men.

The internal consistency of both scales-Attraction to Women and Attraction to Men - was quite satisfactory, with Cronbach's alphas of .98. Thus, they seem adequate from an "absolute" viewpoint (considering the range of values of this coefficient).

The values of the communalities were also high from an absolute perspective. In fact, the lowest value was .55, which corresponds to item 5 . Therefore, the first hypothesis about the bipolar dimensionality of sexual attraction, as evaluated by the SAQ, was supported.

With regard to the second hypothesis (multidimensionality vs. bidimensionality of the instrumental and expressive traits, evaluated with the 12-item BSRI), the results of the PAF are presented in Table 2. The KMO measure of sampling adequacy was .74 . Bartlett's sphericity test $(1552.2, p<.001)$ indicated that the items are related.

As can be observed, there is one factor loading higher than 1 (Item 11). This may cause some surprise, as it is infrequent. However, readers are reminded that, whereas the communality $\left(\mathrm{h}^{2}\right)$ cannot ever be higher than 1 , this does not apply to factor loadings when using oblique rotation, as in this case (Nesselroade \& Cattell, 1988). 
Table 1

Principal Axis Factor Analysis of the SAQ

\begin{tabular}{|c|c|c|c|}
\hline & Items & Factor $^{\mathrm{a}}$ & $\mathrm{h}^{2}$ \\
\hline 16 & In my gang, they know that I am attracted to women & .959 & .920 \\
\hline 12 & When I fall in love with a man, I often think of him & -.955 & .913 \\
\hline 15 & When I go out with a woman I like, I would like us to caress each other & .949 & .900 \\
\hline 6 & My friends think that I like men & -.941 & .885 \\
\hline 8 & I would like to sleep with a woman & .933 & .870 \\
\hline 10 & I find some handsome men very sexy & -.932 & .868 \\
\hline 11 & I would like to engage in sexual relations with a man I choose & -.931 & .867 \\
\hline 4 & I would like to know that a woman is attracted to me & .901 & .812 \\
\hline 1 & When I go out (to bars, discotheques,...) I feel like flirting with women & .899 & .809 \\
\hline 17 & I would like it very much if a man were in love with me & -.897 & .805 \\
\hline 13 & Sometimes I feel like seducing men & -.890 & .792 \\
\hline 3 & At parties, I like to be near (in physical contact with) women & .883 & .779 \\
\hline 14 & If I like a woman a lot, I try to be near her & .852 & .726 \\
\hline 7 & I like to look at photographs of superstars (actors, singers...) if they are attractive men & -.849 & .721 \\
\hline 2 & I like to think that men notice me & -.837 & .701 \\
\hline 9 & I find some female TV presenters very erotic & .833 & .694 \\
\hline 5 & Sometimes I look twice at an ad if there is an attractive woman in it & .741 & .549 \\
\hline
\end{tabular}

Note. ${ }^{\text {a }}$ Statistical significance for factor loadings over or equal to $.30(N=423 ; \alpha=.05$ and power $=.80)$.

Three factors were yielded, explaining $44.8 \%$ of the variance. The first can be called Expressiveness, as it includes all the expressiveness/femininity items. The second one is called Instrumentality, as it is made up of the Instrumentality/masculinity items, and the third, following Bem's (1974) own denomination, should also be called Instrumentality, as it comprises three items that evaluate this theoretical domain.

The most notable aspects of these results are, on the one hand, that the communalities of many of the items are low or very low, and, on the other, that multidimensionality outweighs bidimensionality. The alpha coefficients of these factors were $.77, .82$, and .49 , respectively.

As regards the third hypothesis - the independence of the traits-it can be observed that the correlation between the Expressiveness factor and the second Instrumentality factor is negative $(r=-.150, p<.01)$, whereas the correlation between the first and third factors (Expressiveness and Instrumentality) is positive ( $r=.190$, $p<.01)$. The correlation between the second and third factors, both of Instrumentality/masculinity-which reaches the value of $-.493(p<.01)$ - is difficult, if not impossible,

Table 2

Principal Axis Factor Analysis of the BSRI

\begin{tabular}{|c|c|c|c|c|c|}
\hline & \multirow{2}{*}{ Items } & \multicolumn{3}{|c|}{ Factor $^{\mathrm{a}}$} & \multirow{2}{*}{$\mathrm{h}^{2}$} \\
\hline & & 1 & 2 & 3 & \\
\hline 9 & Warm & .784 & .025 & .009 & .612 \\
\hline 10 & Tender & .741 & .046 & -.128 & .527 \\
\hline 2 & Affectionate & .708 & .100 & .073 & .507 \\
\hline 4 & Sympathetic & .503 & -.077 & .026 & .278 \\
\hline 12 & Gentle & .456 & -.115 & -.039 & .227 \\
\hline 6 & Sensitive to other's needs & .417 & .038 & .058 & .181 \\
\hline 11 & Acts as a leader & -.017 & -1.014 & -.082 & .949 \\
\hline 5 & Leadership ability & .073 & -.788 & .045 & .683 \\
\hline 8 & Dominant & -.165 & -.417 & .366 & .443 \\
\hline 3 & Strong Personality & -.039 & .060 & .818 & .615 \\
\hline 1 & Defends own beliefs & .194 & -.078 & .308 & .190 \\
\hline 7 & Makes decisions easily & .072 & -.197 & .243 & .161 \\
\hline
\end{tabular}

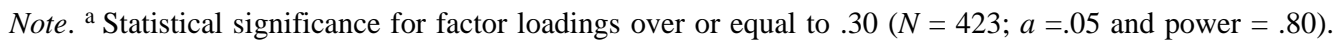


to interpret in line with Bem's original proposals of the mid 70s.

With regard to the fourth hypothesis-different factors operationalize sexual attraction and the instrumental and expressive traits - the data displayed in Table 3 show that quite distinct realities are being analyzed. The first factor is made up of each and every one of the SAQ items, whereas the second and third factors comprise items from the 12item BSRI. The fourth factor seems to be spurious. The joint analysis of these two instruments shows that, whereas the factor structure of the SAQ has not varied, that of the 12item BSRI has changed. Hence, it seems we should go back to bidimensionality rather than multidimensionality. Moreover, the analysis of the communalities revealed the great difference between the two instruments.

With regard to the independence of sexual attraction from the instrumental and expressive traits, the results of the correlation matrix of the factors clearly supported this hypothesis. Thus, when the correlation between factors was considered, Sexual Attraction was clearly independent of Expressiveness (-.072) and Instrumentality (-.085), and of the spurious factor (-.067). Obviously, these values do not reach statistical significance. In contrast, we found a negative correlation $(r=-.204, p<.01)$ between the second and third factors, contrary to initial predictions.

\section{Discussion}

In view of the results obtained, the bipolar dimensionality of the construct of sexual attraction, as measured by the SAQ, receives clear empirical support. Up till now, the empirical studies carried out with this instrument have coincided, because either this bipolar

Table 3

Principal Axis Factor Analysis of the SAQ and BSRI

\begin{tabular}{|c|c|c|c|c|c|c|}
\hline & \multirow{2}{*}{ Items } & \multicolumn{4}{|c|}{ Factor $^{\mathrm{a}}$} & \multirow{2}{*}{$\mathrm{h}^{2}$} \\
\hline & & 1 & 2 & 3 & 4 & \\
\hline S13 & Sometimes I feel like seducing men & .961 & .047 & .008 & .093 & .916 \\
\hline S14 & If I like a woman a lot, I try to be near her & .960 & .031 & -.013 & .022 & .918 \\
\hline S7 & I like to look at photographs of superstars (actors, singers...) if they are attractive men & .946 & -.008 & -.030 & .180 & .912 \\
\hline S10 & I find some handsome men very sexy & -.936 & .046 & .022 & .139 & .927 \\
\hline S4 & I would like to know that a woman is attracted to me & .926 & .026 & -.011 & .228 & .882 \\
\hline S1 & When I go out (to bars, discotheques,...) I feel like flirting with women & .917 & .008 & -.011 & .155 & .848 \\
\hline S8 & I would like to sleep with a woman & -.909 & .029 & .033 & .254 & .933 \\
\hline S9 & I find some female TV presenters very erotic & -.909 & .052 & .038 & .193 & .904 \\
\hline S3 & At parties, I like to be near (in physical contact with) women & .906 & -.002 & -.039 & .237 & .859 \\
\hline S15 & When I go out with a woman I like, I would like us to caress each other & -.884 & -.017 & -.020 & .193 & .838 \\
\hline S11 & I would like to engage in sexual relations with a man I choose & -.872 & .039 & -.012 & .269 & .873 \\
\hline S12 & When I fall in love with a man, I often think of him & .867 & .032 & .048 & .151 & .748 \\
\hline S6 & My friends think that I like men & -.821 & .090 & .021 & .259 & .798 \\
\hline S2 & I like to think that men notice me & -.817 & .057 & -.028 & .294 & .802 \\
\hline S16 & In my gang, they know that I am attracted to women & -.793 & .026 & -.072 & .275 & .742 \\
\hline S17 & I would like it very much if a man were in love with me & .788 & .074 & -.011 & .246 & .662 \\
\hline S5 & Sometimes I look twice at an ad if there is an attractive woman in it & .750 & -.014 & -.042 & .237 & .604 \\
\hline B9 & Warm & .040 & .793 & .023 & -.013 & .615 \\
\hline $\mathrm{B} 10^{\circ}$ & Tender & -.010 & .749 & .130 & -.101 & .527 \\
\hline $\mathrm{B} 2$ & Affectionate & -.068 & .720 & .031 & -.067 & .802 \\
\hline B4 & Sympathetic & .055 & .500 & -.080 & .055 & .882 \\
\hline B12 & Gentle & .081 & .449 & -.069 & .032 & .228 \\
\hline B6 & Sensitive to other's needs & -.089 & .414 & -.012 & .019 & .190 \\
\hline B11 & Acts as a leader & .116 & -.040 & -.843 & -.037 & .723 \\
\hline B5 & Leadership ability & .076 & .052 & -.803 & -.074 & .668 \\
\hline B8 & Dominant & -.042 & -.172 & -.691 & -.005 & .454 \\
\hline B3 & Strong personality & -.120 & .006 & -.481 & .014 & .240 \\
\hline B7 & Makes decisions easily & .135 & .084 & -.357 & .004 & .172 \\
\hline $\mathrm{B} 1$ & Defends own beliefs & -.094 & .190 & -.311 & .053 & .174 \\
\hline
\end{tabular}

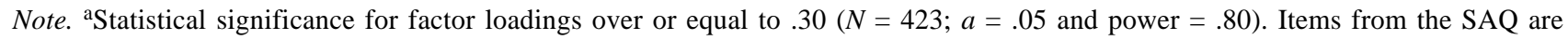
depicted with an S, and items from the BSRI with a B. 
continuum or else the two inversely related dimensions emerge, which amounts to the same thing conceptually and empirically (Fernández, Quiroga, \& Rodríguez, 2006). In fact, in either case, a fourfold typology can be established: people attracted to males (who would score high on one half of the bipolar dimension or on one of the dimensions), people attracted to women (who would score high on the other half of the bipolar dimension or on the other dimension), people attracted to both sexes (who would score high on both poles of the bipolar dimension or on both dimensions), and people not attracted to either sex (who would score low on both poles of the bipolar dimension or on both dimensions). Therefore, the SAQ clearly differentiates individuals (men or women) according to the fourfold typology established in the DSM-IV-TR (APA, 2000). Consequently, from the outlook of sexual attraction and according to these data, the alternatives to this conception (which come from sexual orientation-a broader construct that includes sexual attraction) do not seem to receive empirical support. The classical approach, in effect during the first half of the $20^{\text {th }}$ century, can be discarded because it does not take into account individuals attracted to both sexes or to neither sex; the Kinseyian approach can also be rejected, because, unlike the SAQ, it places people attracted to both sexes in the middle of the continuum instead of at one of the extremes, while it does not, in theory, establish the equivalence of the bipolar continuum and a negatively related bidimensionality. Moreover, the bipolar dimension supported by the data does not match either splitting the Kinseyian continuum into homosexuality, on the one hand, and heterosexuality, on the other (Shively $\&$ De Decco, 1977), or the conception of orthogonal bidimensionality (Storms, 1980). However, what about the advocates of multidimensionality (Klein, 1990; Klein et al., 1985), who include sexual attraction precisely as one of the chief components of sexual orientation? The discrepancy here is with respect to the lack of specification of the dimensions of sexual attraction in these approaches, in contrast to the theory that guided the elaboration of the SAQ. This theory specifies quite clearly that sexual attraction must be a bipolar dimension or two inversely related dimensions.

Although both the reliability (taken as internal consistency) and the validity (construct validity) of the SAQ are guaranteed because replications have produced practically the same results - that is, high internal consistency, high proportion of explained variance, and one bipolar dimension or an inversely related bidimensionality (Fernández, Quiroga, \& Rodríguez, 2006) — these are just the first steps. It would be necessary to verify whether the same results are obtained in university students from other countries, other cultures, and, naturally, in non-university populations. Only after these studies are carried out could these results be extrapolated or generalized to other populations with some rigor. Moreover, in the future, it would be pertinent to verify the factor structure of the SAQ in men and women separately, a task which requires a larger sample than the one used here. Likewise, future studies should include subjects such as transsexuals or ambiguous people, who were not included in this work. In addition, the study of the dimensionality of sexual attraction (our basic aim) should not argue against other analyses such as the determination or conditioning (biological, social) of sexual attraction, its functionality (differences or similarities in different dependent variables), or diverse theoretical perspectives (social, feminist, anthropological). It is reasonable to assume that they would be complementary (Beall \& Sternberg, 1993; Gergen \& Davis, 1997; Rossi, 1985; Talburt \& Steinberg, 2000; Unger, 2001; Worrel, 2001).

With regard to the dimensionality of the traits (the second hypothesis), the results are not at all clear. From one standpoint, when analyzing the 12-item BSRI alone, it seems that one should refer to multidimensionality rather than to bidimensionality, but when conducting a joint analysis with the SAQ, bidimensionality re-emerges. In either case, however, the analysis of the communalities and the proportion of explained variance both indicate that there is considerable room for improvement of this evaluation instrument, at least with these university subjects. These results may indicate that the theory is not solid enough to be able to clarify the constructs of instrumentality and expressiveness and also that the 12-item BSRI does not represent the best possible choice of items for the correct operationalization of these constructs.

In fact, the analysis of the third hypothesis- the relationship between these constructs-taking into account both the results of the 12-item BSRI alone and the conjoint results with the SAQ, seems to provide empirical support to these statements. Why are instrumentality and expressiveness negatively related or why do some instrumentality items have a negative relation with other instrumentality items? Finding theoretical or empirical answers in the original proposals of Bem (1974) and Spence et al. (1975), or even in the theoretical bases of Parsons and Bales (1955), does not seem plausible. Observing these results within the framework of the results obtained with the BSRI in English-speaking countries, the most one can say is that the construct of expressiveness has been relatively better operationalized than that of instrumentality (Choi \& Fuqua, 2003). The masculinity crisis that men are undergoing in practically all societies may have to do with this lack of construct consistency of instrumentality.

Naturally, all these problems negatively affect the most recent conceptions of Bem's $(1981,1993)$ theory of gender schemas when it classifies people as gender-schematic (masculine and feminine) and gender-aschematic (androgynous and undifferentiated) depending on their BSRI scores (the proportion of explained variance does not encourage reliance on this instrument, at least, not when using participants like the ones used in this investigation). 
Our results, therefore, provide more support for the multidimensional gender schema theories, such as the one proposed by Signorella (1999).

With regard to the fourth hypothesis, the data obtained also clearly support that sexual attraction (as measured by the SAQ), a basic core of sex, has little or nothing to do with the instrumental and expressive traits, an essential core of gender, evaluated in turn by the 12-item BSRI.

Taken together, all these data indicate the need to reflect on whether or not it is appropriate to distinguish clearly between sex-at least, when analyzing sexual attractionand gender-at least, when the instrumental and expressive traits are being investigated. If so, perhaps the contemporary ubiquitous fad, which seems to compel authors to substitute gender for sex or to consider both indistinctively, should be reconsidered. This proposal goes far beyond the mere differentiation between sex — considered biological-and gender-understood as social. Among other things, because the development of the complex reality of sex over the life span necessarily includes social aspects, just as the development of the complex reality of gender necessarily starts with sexual dimorphism, whose comprehension must take some biological variables into account. In fact, the theoretical proposals that produced the SAQ (Fernández, 2000) postulated the need to distinguish the science of sexsexology - which includes the study of sexual attraction, from the science of gender-genderology-which includes the investigation of the instrumental and expressive traits. If it was possible to develop a relatively well-founded instrument - the SAQ - based on sexology, surely a better instrument than the BSRI could be developed based on genderology, which could operationalize the instrumental and expressive traits, defined with precision and scientifically based. The consideration of these two quite diverse realities - sex and gender-leads to better understanding of people's development, both from the sexual outlookattracted to both sexes, to neither, to men, or to womenand from the outlook of the instrumental and expressive traits-instrumental and expressive, instrumental, expressive, and non-instrumental-expressive-without the one substituting or encompassing the other (Fernández, Quiroga, $\&$ Del Olmo, 2006). From the standpoint of autonomy and independence, in order to understand the complex reality of sexed and gendered individuals, both entities must be complementary.

\section{References}

American Psychiatric Association (2000). Diagnostic and Statistical Manual of Mental Disorders ( $4^{\text {th }}$ ed., text revision), Washington, DC: Author.

Antill, J.K., \& Russell, G. (1980). A preliminary comparison between two forms of the Bem Sex-Role Inventory. Australian Psychologist, 15, 427-435.
Bakan, D. (1966). The duality of human existence. Chicago, CA: Rand McNally.

Beall, A.E., \& Sternberg, R. J. (Eds.). (1993). The psychology of gender. New York: Guilford Press.

Beere, C. A. (1990). Gender roles: A handbook of tests and measures. New York: Greenwood Press.

Bem, S. (1974). The measurement of psychological androgyny. Journal of Consulting and Clinical Psychology, 42, 155-162.

Bem, S. (1981). Gender schema theory: A cognitive account of sex typing. Psychological Review, 88, 354-364.

Bem, S. (1985). Androgyny and gender schema theory: A conceptual and empirical integration. In T.B. Sonderegger (Ed.), Nebraska Symposium on motivation, 1984: Psychology and gender (Vol. 32, pp. 179-226). Lincoln, NB: University of Nebraska Press.

Bem, S. (1993).The lenses of gender: Transforming the debate on sexual inequality. New Haven, CT: Yale University Press.

Berkey, B. R., Perelman-Hall, T., \& Kurdek, L. A. (1990). The Multidimensional Scale of Sexuality. Journal of Homosexuality, 19, 67-87.

Choi, N., \& Fuqua, D. R. (2003). The structure of the Bem Sex Role Inventory: A summary report of 23 validation studies. Educational and Psychological Measurement, 63, 872-887.

Coleman, E. (1987). Assessment of sexual orientation. Journal of Homosexuality, 14, 9-24.

Constantinople, A. (1973). Masculinity-femininity: An exception to the famous dictum? Psychological Bulletin, 80, 389-407.

Davis, C. M., Yarber, W. L., Bauserman, R., Schreer, G., \& Davis, S. L. (1997). Handbook of sexuality-related measures. Thousand Oaks, CA: Sage.

Desrochers, S. (1995). What types of men are most attractive and most repulsive to women? Sex Roles, 32, 375-392.

Evans, D.T. (1993). Sexual citizenship: The material construction of sexualities. London: Routledge.

Fernández, J. (Coord.). (2000). Intervención en los ámbitos de la sexología y de la generología. [Sexological and genderological Intervention]. Madrid: Pirámide.

Fernández, J., Quiroga, M. A., \& Del Olmo, I. (2006). Is there any relationship between sexual attraction and gender typology? The Spanish Journal of Psychology, 9, 3-9.

Fernández, J., Quiroga, M. A., \& Rodríguez, A. (2006). Dimensionalidad de la atracción sexual [Sexual attraction: Its dimensionality]. Psicothema, 18, 392-399.

Finlay, B., \& Scheltema, K.E. (1991). The relation of gender and sexual orientation to measures of masculinity, femininity, and androgyny: A further analysis. Journal of Homosexuality, 21, 71-85.

Gallagher, L.A. (Ed.). (2005). Thesaurus of psychological index terms $\left(10^{\text {th }}\right.$ ed.). Washington, DC: American Psychological Association.

Geer, J.H., \& O’Donohue, W.T.(Eds).(1987). Theories of human sexualities. New York: Plenum Press.

Gergen, M.M., \& Davis, S.N. (Eds.).(1997). Toward a new psychology of gender: A reader. New York: Routledge. 
Green, B., \& Kendrick, D. (1994). The attractiveness of gender type traits at different relationship levels: Androgynous characteristics may be desirable after all. Journal of Personality and Social Psychology, 20, 244-253.

Greene, B., \& Croom, G.L. (Eds.). (2000). Education, research, and practice in lesbian, gay, bisexual, and transgendered psychology: A resource manual (Vol. 5). Thousand Oaks, CA: Sage.

Gough, H. G. (1952). Identifying psychological femininity. Educational and Psychological Measurement, 12, 427-439.

Hathaway, S. R., \& McKinley, J. C. (1943). The Minnesota Multiphasic Personality Inventory. New York: Psychological Corporation.

Helgeson, V. (1997). Relation of agency and communion to wellbeing: Evidence and potencial explanations. Psychological Bulletin, 116, 412-428.

Kinnish, K.K., Strassberg, D.S., \& Turner, C.W. (2005). Sex differences in the flexibility of sexual orientation: A multidimensional retrospective assessment. Archives of Sexual Behavior, 34, 173-183.

Kinsey, A. C., Pomeroy, W. B., \& Martin, C. E. (1948). Sexual behavior in the human male. Philadelphia: Saunders.

Kitzinger, C. (2001). Sexualities. In R. Unger (Ed.), Handbook of the psychology of women and gender (pp. 272-285). New York: Wiley.

Klein, F. (1990). The need to view sexual orientation as a multivariable dynamic process: A theoretical perspective. In D. P. McWhirter, S. A. Sanders, \& J. M. Reinisch (Eds.), Homosexuality/heterosexuality: Concepts of sexual orientation (pp. 277-282). New York: Oxford University Press.

Klein, F., Sepekoff, B., \& Wolf, T. J. (1985). Sexual orientation: A multi-variable dynamic process. Journal of Homosexuality, $11,35-49$.

Koestler, A. (1967). The ghost in the machine. London: Hutchinson.

Koestler, A. (1978). Janus. A summing up. New York: Vintage Books.

Lippa, R.A. (2005). Gender, nature, and nurture (2nd. ed.). Mahwah, NJ: LEA.

Mateo, M. A., \& Fernández, J. (1991). La dimensionalidad de los conceptos de masculinidad y feminidad [The dimensionality of the concepts of masculinity and femininity]. Investigaciones Psicológicas, 9, 95-116.

Marsh, H. W., Antill, J. K., \& Cunningham, J. D. (1989). Masculinity and femininity: A bipolar construct and independent constructs. Journal of Personality, 57, 625-663.

Narring, F., Stronski Huwiler, S.M., \& Michaud, P-A. (2003). Prevalence and dimensions of sexual orientation in Swiss adolescents: A cross-sectional survey of 16 to 20-year-old students. Acta Paediatrica,92, 233-239.

Nesselroade, J. R., \& Cattell, R. B. (Eds.). (1988). Handbook of multivariate experimental psychology ( $2^{\text {nd }}$ ed.). New York: Plenum Press.
Parsons, T., \& Bales, R. F. (Eds.). (1955). Family, socialization, and interaction process. New York: Free Press.

Rossi, A.S. (Ed.).(1985). Gener and the life course. New York: Aldine.

Rossi, A.S. (Ed.).(1994). Sexuality across the life course. Chicago, CA: The University of Chicago Press.

Sell, R. L. (1997). Defining and measuring sexual orientation: A review. Archives of Sexual Behavior, 26, 643-658.

Shively, M. G., \& De Decco, J. P. (1977). Components of sexual identity. Journal of Homosexuality, 2, 41-48.

Signorella, M.L. (1999). Multidimensionality of gender schemas: Implications for the development of gender-related characteristics. In W.B. Swann, Jr., J.H. Langlois, \& L.A. Gilbert (Eds.), Sexism and stereotypes in modern society: The gender science of Janet Taylor Spence (pp. 107-126). Washington, DC: American Psychological Association.

Spence, J. T. (1991). Do the BSRI and the PAQ measure the same or different concepts? Psychology of Women Quarterly, 15, 141-165.

Spence, J., \& Buckner, C. (2000). Instrumental and expressive traits, trait stereotypes, and sexist attitude: What do they signify? Personality of Women Quarterly, 24, 44-62.

Spence, J., Helmreich, R., \& Holahan, C. (1979). Negative and positive components of psychological masculinity and femininity and their relationship to self-reports of neurotic and acting out behaviours. Journal of Personality and Social Psychology, 37, 1673-1682.

Spence, J., Helmreich, R., \& Stapp, J. (1975). Ratings of self and peers on Sex Role Attributes and their relation to self-esteem and conceptions of masculinity and femininity. Journal of Personality and Social Psychology, 32, 29-39.

Stake, J.E. (1997). Integrating expressiveness and instrumentality in real-life settings: A new perspective on the benefits of androgyny. Sex Roles, 37, 541-564.

Storms, M. D. (1980). Theories of sexual orientation. Journal of Personality and Social Psychology, 38, 783-792.

Talburt, S., \& Steinberg, S.R. (Eds.).(2000). Thinking queer: Sexuality, culture, and education. New York: Peter Lang.

Terman, L. M., \& Miles, C. C. (1936). Sex and personality. New York: McGraw-Hill.

Unger, R. K. (Ed.). (2001). Handbook of the psychology of women and gender. New York: Wiley.

Worrell, J. (Ed.).(2001). Encyclopedia of women and gender (Vols. 1 and 2). New York : Academic Press.

Zhang, J, Norvilitis, J.M., \& Jin, S. (2001). Measuring gender orientation with the Bem Sex Role Inventory in Chinese culture. Sex Roles, 44, 237-251.

Received February 22, 2006 Review received May 10, 2006 Accepted July 5, 2006 